\title{
Cáncer y territorio. Un recorrido por las continuidades y discontinuidades espaciales proyectadas por este actor no humano*
}

Cancer and Territory. A Journey through the Continuities and Spatial Discontinuities Projected by this Non-human Actor Cancro e território. Um recorrido pelas continuidadese descontinuidades espaciais projetadas por este ator não humano

Milton Velásquez Arias*

Recibido: 28 de septiembre de 2018

Aprobado: 6 de febrero de 2019

Doi: https://www.doi.org/10.12804/revistas.urosario.edu.co/territorios/a.7282

Para citar este artículo:

Velásquez Arias, M. (2020). Cáncer y territorio. Un recorrido por las continuidades y discontinuidades espaciales proyectadas por este actor no humano. Territorios (42), 1-25. Doi: https://www.doi.org/10.12804/ revistas.urosario.edu.co/territorios/a.7282

* Este artículo es el resultado de la investigación titulada Cáncer y territorios, realizada en el marco de la Maestría en Estudios Territoriales, dirigida por el Dr. Adolfo León Grisales Vargas.

** Universidad de Caldas. Instituto de Investigaciones en Ciencias Sociales y Humanas (ICSH). Correo electrónico: velasquezamc@gmail.com. ORCID: https://orcid. org/0000-0001-6489-0653 
Palabras clave

Territorio, cáncer, actor social, continuidad, centro de tratamiento.

Keywords

Territory, cancer, social actor, continuity, treatment center.

Palavras-chave

Território, cancro, ator social, continuidade, centro de tratamento.

\section{tersitarias 42}

RESUMEN

El presente artículo se centra concretamente en develar la relación entre Cáncer y territorio, en especial, la manera como, a partir del diagnóstico de esta enfermedad, el Cáncer, asumido como un actor social no humano, incide en la construcción territorial de los espacios de vida cotidiana, desde su concepción y significación hasta su gestión y uso. Para esto, se utilizó una estrategia metodológica cualitativa fundamentada en estudio fenomenológico, que se centró en identificar las prácticas y los discursos que objetivan las nuevas configuraciones territoriales. Se trabajó con diez enfermos de distintos tipos de cáncer y con diez especialistas de la Unidad Oncológica Oncólogos del Occidente situada en el Eje Cafetero. Entre los principales hallazgos, se muestra cómo la relación Cáncer y territorio implica, entre otras cosas, una vuelta de tuerca sugerente para los estudios del territorio contemporáneos, en tanto permite entrever que el territorio, como una construcción social y cultural de los actores sociales, es una producción y/o significación hecha no solo a la medida de los humanos, sino también, a la medida de los actores no humanos que entran en disputa y en tensión con las dinámicas mismas que posibilitan la configuración y ordenación de un espacio apropiado.

\section{ABSTRACT}

The present article focuses on unveiling the relationship between cancer and territory. This relationship arises in the understanding of how cancer, as a non-human social actor, affects the territorial construction of spaces in daily life from its conception and connotation to its management and use of space. We worked with ten cancer patients and ten specialists from an Oncology Unit, Oncólogos de Occidente, located in the coffee axis. We used a qualitative methodological strategy based on a phenomenological study that focuses on revealing the practices and discourses that objectify the new territorial configurations. Among the main findings is how the relationship between cancer and territory entails a novel perspective for contemporary territorial studies, which allows understanding territory as a social and cultural construction of the social actors that is not only gestated to the measure and signification of humans. Also, the territory is tailored by the non-human actors who come into dispute and in constriction with the very dynamics that facilitate the configuration and ordination of an appropriate space.

\section{RESUMO}

O presente artigo centra-se concretamente em desvelar a relação entre cancro e território, especialmente, a maneira como, a partir do diagnóstico desta doença, o cancro, assumida como um ator social não humano, incide na construção territorial dos espaços de vida cotidiana, desde sua conceição e significação até sua gestão e uso. Para isto, se utilizou uma estratégia metodológica qualitativa fundamentada em estudo fenomenológico, que se centrou em identificar as práticas e os discursos que objetivam as novas configurações territoriais. Se trabalhou com dez doentes de diferentes tipos de cancro e com dez especialistas da Unidade Oncológica Oncólogos el Occidente situada no Eixo Cafeeiro. Entre os principais resultados, se mostra como a relação cancro e território implica, entre outras coisas, uma nova reviravolta sugestiva para os estudos do território contemporâneos, enquanto permite entrever que o território, como uma construção 
social e cultural dos atores sociais, é uma produção e/ou significação feita não só à medida dos humanos, mas também, à medida dos atores não humanos que entram em disputa e em tensão com as dinâmicas mesmas que possibilitam a configuração e ordenação de um espaço apropriado.

\section{Introducción}

La relación Cáncer y territorio suele pensarse en términos de cuestiones de salud pública, referidas a la prevalencia de la enfermedad en determinados lugares; sin embargo, la intención de este artículo es más bien mostrar de qué manera una enfermedad como el Cáncer tiene implicaciones territoriales profundas. ${ }^{1}$

Para el estudio de estas dos categorías de análisis, la investigación matriz, denominada Cáncer y territorios (Velázquez, 2018), partió de dos vivencias: por una parte, mi labor por más de tres años como trabajador social en la clínica o unidad oncológica de Oncólogos de Occidente localizada en el Eje Cafetero ${ }^{2}$ y, por otra, la experiencia de mi padre, que fue diagnosticado con un cáncer de próstata a mediados del 2008.

En la clínica, sin duda alguna, no solo me enfrenté a la ferocidad de esta enfermedad y a los padecimientos de los enfermos, sino que también encaré la sensación de estar en territorios distintos a los míos cuando.

En esta clínica - en la que solo se trata el Cáncer, enfermedad a la cual se le tiene un temor especial - me sentía despojado de mi territorio portado (Nates, 2010), ciertamente, de la estructura discursiva y práctica con la que normalmente transitaba y frecuentaba mi casa, la universidad, las bibliotecas, las calles, los medios de transporte, entre otras escalas de representación y relacionamiento con el espacio. En términos generales, me sentía paradójicamente fuera de mí o, como lo explica extraordinariamente Jean LucNancy (2007), como un intruso en mí mismo, en tanto me sentía extraño en los territorios del Cáncer.

Una sensación de quiebre generada en principio por la enfermedad en sí (temor) y por los tratamientos utilizados (violentos), y con especial preponderancia, por los espacios que constituyen las clínicas oncológicas como la sala de quimioterapia, el bunker de radioterapia, la sala de braquiterapía y la sala de espera que se caracterizan por ser lúgubres (allí se escuchan los pasos de la muerte), estériles (ya que no hay posibilidad de decoración alguna), agresivos (por los tratamientos que intervienen el cuerpo), pequeños (porque solo hay espacio para la cama y el mueble del acompañante) y ajustados a una multiplicidad de normas y reglas (administrados espacialmente por el equipo médico), lo que no da posibilidad alguna, para que sean vividos o al menos organizados de conformidad con ese territorio cargado o significado por cada uno de los actores.
Hay, al menos, otra enfermedad en la que son evidentes las implicaciones territoriales: la lepra (basta con revisar la historia del municipio de Agua de Dios); sin embargo, el Cáncer impone modos diferentes de territorialización e implica otros territorios, otras continuidades, además, el Cáncer tiene, por asi decirlo, otro carácter.

${ }^{2}$ Asumimos como Unidad de Análisis de esa gran región conformada por las ciudades de Manizales, Pereira y Armenia, en las que Oncólogos de Occidente ofrece servicios en esta materia tanto a nivel ambulatorio como a nivel de hospitalización.

territarias 42

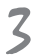


${ }^{3}$ La Carta de París es un documento simbólico en el cual se mencionan las disposiciones esenciales para combatir el Cáncer en el nuevo milenio. Se trata de un documento constituido por 10 artículos para erradicar este mal $y$ las diferentes consecuencias asociadas con él, como el estigma cultural, entre otros asuntos. La elaboración de este documento simbólico fue motivada por el jefe de departamento de Oncología del Hospital de la Piti Salpde Paris, David Khayat y por su colega del Anderson Center de Houston de los Estados Unidos, Gabriel Hortobagyi.

\section{territarias 42}

Estas territorializaciones de los espacios de la clínica oncológica, como el modo en que se atiende al enfermo, responden, entre otras cosas, a los protocolos y modelos concertados a nivel internacional por medio de la carta de París $^{3}$ y a otras disposiciones determinadas por la Organización Mundial de la Salud (OMS), que se han materializado en Colombia por medio de la Ley 100 de 1993, la Ley 1384 (Ley Sandra Ceballos), Ley 1388 de 2010 (Ley de Cáncer Infantil) y por la Resolución 1383 de 2013, por la cual se adopta el plan decenal para el control de Cáncer en Colombia 2012-2021. Estas disposiciones rigen tanto el obrar médico, como la construcción, organización y uso de los lugares en los que se trata esta enfermedad en particular.

La segunda vivencia, que corresponde a la experiencia de mi padre, diagnosticado con un cáncer de próstata a mediados del 2008, representó una fractura familiar, simbólica y social, ya que la enfermedad implicó una transformación de las dinámicas discursivas y prácticas de él y de mi familia, así como un cambio de las trayectorias y de los modos de apropiación de aquellos espacios que eran paulatinamente frecuentados y habitados. En mi caso, por ejemplo, pasé de ir de la casa a la universidad, a ir de la casa a la clínica y, luego, a la universidad o viceversa.

La objetivación de estas dos vivencias en el espacio mismo de la investigación significó, entre otras cosas, plantearme como eje de trabajo dos hipótesis que aportan a la discusión de los problemas territoriales contemporáneos y, también, a la configuración de lo que he llamado una 'geografía cultural de la salud', en clave del territorio y de los actores, sean estos humanos o no humanos, que participan significativamente en este tipo de procesos.

La primera hipótesis tiene que ver con que lo que le ocurre física y simbólicamente al cuerpo, le ocurre, en igual medida, a los territorios habitados por el cuerpo que ha sido apropiado por el Cáncer. De la misma manera en la que el propio cuerpo se hace dolorosamente visible para la conciencia a partir de la enfermedad, ocurre igualmente algo parecido con el territorio: que la enfermedad hace también dolorosamente visible para la conciencia el territorio habitado y vivido. Como si estar enfermo fuera, entonces, no solo sentir y saber del propio cuerpo, sino de igual forma sentir y saber del propio territorio vivido.

La segunda hipótesis se refiere a la idea de que el Cáncer, como actor social no humano, constituye una entidad con agencia estructurante uniforme y dominante (Giddens, 1995), que sugiere modos en que los territorios son organizados, gestionados y manejados. En virtud de esto, se puede decir que es el Cáncer el que establece las condiciones sobre las cuales se materializarán las acciones y las prácticas que, en último término, impactarán paulatinamente las estrategias de apropiación de cada uno de estos espacios. 
Ambas hipótesis permiten pensar que, en el fondo, este actor no humano es susceptible de ponerse en tensión no solo con la escala del cuerpo mismo de quien se ve afectado (la mayoría de trabajos han avanzado en este horizonte), sino también, con otras escalas de representación y organización del mundo como lo son la cama, la habitación, la casa, el barrio, la oficina de trabajo, la universidad, la ciudad y el vasto mundo; producto de su capacidad de agencia que representa en sí mismo su estructura, y la estructura médico-discursiva que lo rodea.

De este modo, este artículo versa sobre la relación entre Cáncer y territorio, específicamente, entre las construcciones territoriales acaecidas, a partir del diagnóstico (hito territorial) de esta enfermedad, sobre los espacios de la vida cotidiana de los actores sociales ahora enfermos. Para este trabajo, el Cáncer no es asumido estrictamente como un problema de salud pública o como una enfermedad de carácter universal (aunque lo es y lo seguirá siendo), sino que se toma como un actor social no humano que media, justamente, en las dinámicas y en las configuraciones territoriales producidas por los demás actores, sean humanos o no, que participan de la estructura social.

Como actor social no humano, el Cáncer se asume como un auténtico organismo que puebla y conquista el entramado del mundo (Latour, 2008), en la medida en que objetiva, delimita, agencia y transforma el estado y las dinámicas mediante las cuales los objetos se presentan en las interacciones que conforman la sociedad y el territorio, ya que dispone de otros medios, fuerzas y caminos para que dichas acciones se materialicen en lo social $y$, en específico, en lo territorial, como se ha mencionado con antelación. Dicho en otras palabras de Latour (2008) "la acción social no solo es controlada por extraños, también es desplazada y delegada a distintos tipos de actores que son capaces de transportar la acción a través de otros modos de acción, otros tipos de fuerzas completamente distintos" (p. 105).

Esto no quiere decir que el Cáncer llegue a reemplazar a los humanos en la producción de las acciones que posibilitan la organización espacial, lo que significa es que, al situarse en el centro de las dinámicas sociales como un organismo “vivo", posibilita y cataliza otras acciones, y también interfiere preponderantemente en la estructura social y, en especial, en la gestión espacial, como cualquier otro actor, ya que impone a las acciones unos discursos de medicalización que paulatinamente cambian la forma en que los territorios de la vida cotidiana están dispuestos.

Un ejemplo de lo anterior, son las nuevas trayectorias que impone a los actores afectados, como ir de la casa a la clínica y de esta a la casa, además de las modificaciones físicas que gradualmente va generando en cada uno de los territorios de la vida cotidiana, como cambiar la cama o disponer en la habitación de un espacio para los medicamentos. territarias 42

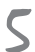


${ }^{4}$ La particularidad de la investigación realizada fue que se decidió dejar la puerta abierta para trabajar con diferentes tipos y escalas del cáncer, ya que cada uno supone, como se ha mencionado al inicio de la introducción, una manera en que el territorio se construye y se apropia por los actores. Adicional a esto, los participantes fueron escogidos aleatoriamente, tiendo en cuenta por una parte su estado de activo en algún tratamiento, asi como su interés de participar en la Investigación.

territarias 42
El Cáncer, en este orden de ideas, es tanto producto como productor de lo social, no es solamente un producto discursivo elaborado por una comunidad médica, evidentemente, la frontera de lo médico ha sido traspasada y el Cáncer ya no puede ser entendido solo desde su relación causal (salud/enfermedad), sino que, a su vez, es necesario entenderlo a partir de este tipo de estudios en los cuales la perspectiva territorial es clave, la experiencia de esta enfermedad debe ser asumida como un proceso estructural de carácter esencialmente material y simbólico que determina y disloca las relaciones sociales y espaciales, ya que obliga a que los demás actores actúen de cierta forma (Latour, 2008), es decir, induce a que los otros actores que participan de lo social "actúen" bajo otras condiciones y circunstancias.

Respecto al territorio, en este artículo, se entiende como una construcción social y cultural proyectada por los actores humanos (Nates, 2010), que resulta, en este caso, como un producto de las mediaciones, encuentros, pugnas discursivas y prácticas proyectadas tanto por los actores humanos (enfermos, especialistas y acompañantes) como por los actores no humanos (tratamientos, medicamentos, células cancerosas) que participan de la objetivación y organización de esta estructura.
En términos metodológicos, la investigación ha sido cualitativa, fundamentada en un estudio fenomenológico, con un gran nivel de detalle en los trabajos etnográfico y autoetnográfico, por medio de los cuales fue factible el cruce de la mirada objetivante e imparcial del trabajo científico con la propia experiencia laboral y la mirada íntima, subjetiva, orientada al cuidado y a la compasión del trabajo social. Se trabajó con diez enfermos de distintos tipos de cáncer y con diez especialistas. ${ }^{4}$ Tanto los enfermos como los especialistas se encontraban distribuidos entre las ciudades de Armenia, Pereira y Manizales (Velázquez, 2018).

La metodología se objetivó en la etnografía y en la autoetnografía, en la medida en que se priorizaron los discursos y las prácticas mediante los cuales los actores humanos, como los enfermos y los especialistas, acotan, delimitan, objetivan y dan sentido al nuevo orden establecido por este actor no humano. La etnografía, a su vez, fue asumida, también, como el método que posibilitó el desarrollo y la articulación de una serie de técnicas e instrumentos de recolección de información como la entrevista semiestructurada, la observación participante, la descripción, el dibujo, la revisión de fuentes secundarias y una serie de cartografías asociadas con una temporalidad del antes y del después del hito territorial. 


\section{El Cáncer: una entidad estructurante que incide territorialmente}

El espacio es la prisión original, el territorio es la prisión que los hombres se dan a sí mismos. Raffestin (2011, p. 102).

El Cáncer, asumido como un actor social no humano, actúa sobre el espacio, puesto que goza de una doble condición o carácter de agencia, que le permite interferir física y simbólicamente en las dinámicas relacionales que se establecen entre los actores y el espacio de la vida cotidiana, sea la habitación, la cama, la casa, el barrio o la ciudad entera. En primer lugar, se refiere a la capacidad de agencia implícito en su impacto en la vida física, social y espacial de los actores y, en segundo lugar, concierne a su presencia como agente en el ámbito de las prácticas y de los discursos de medicalización que se imponen posterior de su hito (diagnóstico) a cada uno de los enfermos de manera particular.

A propósito de lo primero, me refiero a esa capacidad de imponer un nuevo orden y modo en que los espacios de la vida cotidiana son apropiados, por ejemplo, bajo esta nueva condición del actor, los espacios en los que suele frecuentar son rediseñados, ya sea desde la posición y ubicación de la cama del enfermo, hasta su esterilización diaria. Y lo segundo, tiene que ver con las restricciones que se le imponen al enfermo de ir o no ir a ciertos espacios, en especial, a aquellos de carácter público como los centros comerciales, la oficina de trabajo, el estadio y el café, entre otros, en los cuales el enfermo puede estar en riesgo y, en caso de que los frecuente, debe hacerlo con tapabocas y en horarios no muy concurridos.

La coexistencia de ambos modos de agencia mediante los cuales el Cáncer se proyecta permite, en este caso, dar cuenta de la transformación de los espacios y, a la vez, también percatarse de una serie de redes de lugares que se conectan a partir de la materialización del hito territorial que implica, por ejemplo, que el enfermo se encuentre ante una nueva ciudad, un nuevo barrio, una nueva vereda, una nueva comuna, una nueva casa y una nueva habitación ; ${ }^{5}$ ya que, de acuerdo a Yi Fu-Tuan (2007), "el dolor [tanto como el Cáncer mismo que lo produce] constituye una manera de conocer el mundo o de ampliarlo más allá de lo conocido y producido por el actor" (p. 71, las cursivas son mías).

Bajo esta perspectiva, es claro que ya no es el sujeto que se hace así mismo su prisión, como lo sugiere Claude Raffestin (2011), ya no es él quien delimita una porción del espacio para hacerlo suyo, es el Cáncer, como un actor estructurante, el que forja nuevas delimitaciones o prisiones sobre las cuales discurrirá a partir del hito (diagnóstico) la vida del enfermo. La cama, la habitación de la casa, la casa, la habitación de la clínica, la sala de quimioterapia y radioterapia, entre otros, son,
5 Nueva, especificamente, en términos simbólicos y culturales, mas no en términos físicos o arquitectónicos. Aunque en ocasiones lo nuevo implica tanto lo simbólico como lo físico, esto último, porque los médicos sugieren al enfermo cambiar de casa. 
6 Con estas metáforas me refiero a una serie de hechos que tuvieron lugar en los Estados Unidos en la Presidencia del Sr. Richard Nixon, quien, mediante la ley Nacional del Cáncer de 1971, le declaró la guerra oficial al Cáncer, para ello, lo doto de personalidad. Evidentemente Nixon no derroto al Cáncer, pues aún lo padecemos, no obstante, sí cambió la retórica y manera en que nos referimos a él.

\section{tersitarias 42}

por ejemplo, espacios estereotipados por este actor no humano.

La prisión que se hace a sí misma esta enfermedad se materializa o se representa no solo en las metáforas guerreristas o políticas, ${ }^{6}$ sino, a su vez, en lo que hemos denominado el centro de tratamiento, visto como la correlación entre la clínica, la casa y el albergue, en la medida que son producciones y objetivaciones particulares de este actor.

En consecuencia, el centro de tratamiento, entendido como una correlación de cosas, de lugares, de discursos, de prácticas, de objetos y de actores, no solo representa el espacio en el cual se trata el cáncer, a su vez, representa una continuidad y una discontinuidad territorial que conecta una serie de marcaciones y/o prisiones inversas construidas por este actor, que finalmente entran en tensión con las jurisdicciones de los actores sociales.

Frédéric Giraut (2013) entiende la continuidad como un 'territorio multisituado', en la medida en que da cuenta de una serie de entidades espaciales asociadas y conectadas con lugares contiguos o no contiguos que comparten una objetivación social y cultural coherente, es decir, una territorialidad compartida que ha sido construida en función de una serie de estereotipos, normas y experiencias establecidos, en este caso, por el Cáncer. Lo multisituado funge como una especie de ordenador de la multiplicidad de territorialidades que comparten o llegan a compartir algún tipo de vínculo físico o simbólico.

A su vez, el centro de tratamiento representa una discontinuidad, ya que la homogeneidad territorial en la cual el sujeto habitaba antes de la enfermedad, representada en la casa, la oficina de trabajo, la universidad y los lugares de ocio se ve enteramente fracturada simbólicamente, inclusive, llegan a desaparecer de la vida del actor producto de la imposición de normas de estar y de habitar mencionados territorios. Dicho en otras palabras, se establece sobre la continuidad territorial de los actores sociales, otra continuidad estereotipada por el Cáncer en la que el enfermo, según Víctor Turner (1980), “no encuentra muy pocos o ningún atributo, tanto del estado pasado como del venidero" (p. 104).

En esta nueva continuidad o discontinuidad el enfermo no llega a encontrar ninguna relación o coincidencia, puesto que se ha desterritorializado toda la estructura significativa que había construido en el marco del desarrollo de la vida cotidiana (Haesbaert, 2004). El enfermo se ve significativamente separado de dicha estructura, lo que lo obliga voluntaria o involuntariamente a romper con cada una de las relaciones y representaciones construidas antes del hito territorial del Cáncer.

En este sentido, el actor, en el espacio apropiado, delimitado y ordenado por el Cáncer, pierde ciertas cualidades, rasgos, 
costumbres y discursos de su estructura personal e íntima. Tanto así que el actor y el territorio se hacen otros, ya que es otra la jurisdicción que se interioriza para ajustarse a las nuevas dinámicas coyunturales establecidas por este actor no humano. Este proceso ambiguo de lo uno y de lo otro representa un proceso de desterritorialización y reterritorialización (Vergara, 2017) en el que el actor abandona una dinámica socioespacial y se incorpora a una nueva, en este caso, establecida por el Cáncer, que se hace tangible en la continuidad territorial acotada por la clínica, la casa y el albergue, como se verá a continuación.

\section{La clínica y la ventana}

En principio, es preciso destacar que la clínica es entendida, de acuerdo con Michel Foucault (2012), como "la reorganización en profundidad no solo del discurso médico, sino de la posibilidad misma de un lenguaje sobre la enfermedad" (p. 21) $\mathrm{y}$, a su vez, como la posibilidad de un lenguaje y de un modo de estar sobre el mundo, sobre la realidad y sobre los espacios acotados y delimitados por los sujetos. En este sentido, la clínica representa un carácter estructurante de acuerdo con el cual se habitan los demás territorios, que, en este caso, se construyen a partir de un estar de espaldas a los territorios reales (Bozzano, 2000).

La clínica, en este orden de ideas, se erige como un orden en el que la estructura de la sociedad se vive y se gestiona. En efecto, la clínica representa una condición o carácter inverso a la manera como nos apropiamos de los territorios en lo cotidiano. Se trata de toda una estructura viva que está del otro lado de esta estructura "real" (de la nuestra como sujetos sanos), pero que incide práctica y discursivamente en la forma como se manejan los espacios del mundo exterior e interior. De ahí que los demás territorios como la ciudad, la casa, la habitación y el cuerpo se comiencen a experimentar como una extensión de las dinámicas de la clínica.

Esta es una nueva organización del mundo que se materializa en virtud de la profanación del yo de los actores sociales por parte del actor no humano (Goffman, 2001). Dicha profanación implica, en este caso, la proyección de una condición de ser y de estar sobre el vasto espacio que hemos denominado estar de espaldas, en la cual los actores sociales mantienen una realidad física mas no simbólica con el espacio o realidad habitada; ambiguamente, se edifica una relación con el mundo en la cual el actor se vincula con el resto de la estructura desde una suerte de negación que genera u ocasiona que los enfermos experimenten la sensación de estar, literalmente, alejados y subsumidos a las particularidades, intereses y circunstancias establecidos por el Cáncer.

De esta manera, los territorios son ajustados por este actor, más no por el sujeto. El sujeto enfermo ahora los vive, los habita y, en ocasiones, los hace suyos territarias 42

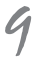


7 Se utiliza la expresión 'negación' para dar cuenta de la disputa territorial entre el sujeto y el cáncer, en la que la enfermedad establece sobre las territorialidades del sujeto otra forma de organizar, gestionar $y$ hasta de producir los espacios de la vida cotidiana. Por lo tanto, con esto no estamos haciendo alusión a que el sujeto esté literalmente fuera del territorio; esto, de entrada, es epistemológicamente imposible de pensar, en tanto el sujeto o el actor siempre estará práctica o discursivamente en el territorio, nunca estará fuera de este.

\section{territarias 42}

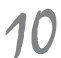

por diversos rituales, dicho en otras palabras, los ajusta en la medida en que los conoce y se familiariza con ellos.

Es el actor no humano que dispone de ellos, como dispone del cuerpo y ese disponer implica indudablemente un negar el territorio del otro, en este caso, del enfermo, y ese negar en consecuencia ${ }^{7}$ hace que el enfermo experimente sus propios territorios incómodo, como si fuera un intruso en sí mismo, inclusive, se siente intruso en su propio cuerpo (Nancy, 2007). Es decir, se siente en otro cuerpo, como a su vez, y a raíz de la experiencia del cáncer, se siente incómodo e intruso en sus territorios habitados o frecuentados, como lo deja ver uno de los enfermos entrevistados al llegar a su propia casa después de varios meses de hospitalización en la clínica:

El primer día que yo llegué a mi casa, yo me hacía demasiadas preguntas cuando veía a mis hermanos correr, brincar y jugar en nuestra casa. Yo los veía y yo sin poder hacer eso todavía, porque mi cuerpo obviamente estaba muy débil por tanto tratamiento, el cuerpo no tenía esa reacción que tenía antes, no tenía tantas limitaciones como antes. Y estas limitaciones e imposibilidades de compartir, pero, ante todo, de vivir libremente el espacio hace que la persona se haga transparente frente a los demás, invisible, ya que uno siente que no lo están viendo así uno esté en el mismo lugar donde están los otros, uno desaparece de la vida de los demás, así uno esté allí físicamente.
Es como que lo visible que era, se hace invisible producto del Cáncer (Rojas, 2017).

Estar de espaldas, no solo se refiere a la negación espacial, sino también, a la invisibilización, a un desaparecer en la medida en que el actor, digámoslo de alguna manera, es privado de vivir autónomamente en el espacio, ya que la experiencia del cuerpo no compagina con la realidad del espacio, puesto que el cuerpo, en este caso, carga consigo una serie de recomendaciones y restricciones que no le permiten, de momento, acceder a ese espacio que no ha sido ajustado a la experiencia del cuerpo.

Este es el caso de Ernesto Rojas, quien, al llegar a casa, como producto de su nueva condición de actor enfermo, no puede vincularse a la realidad de ese espacio que corresponde al juego con los hermanos. Esa imposibilidad para vincularse, le hace experimentar una clase de sensación en la que el enfermo no solo está atrás de esa realidad, sino que también es un ser invisible a los ojos de quienes están sanos ausentes de anormalidad física o emocional.

Así, es claro que estar de espaldas es una experiencia generada por la enfermedad $y$, por consiguiente, es un modo de construcción social del territorio que se siente cuando se está en la clínica y, a su vez, es una impresión que se expande después del primer ingreso y egreso de la clínica a las demás escalas territoriales del sujeto, como se vio en el caso de Ernesto Rojas. 
La sensación de estar de espaldas se construye como manifestación de una inferioridad que se materializa en un invisibilidad espacial del sujeto; ciertamente, el sujeto, producto de su nuevo estado, en el cual ha perdido autonomía, libertad y gestión de su vida cotidiana en vínculo con el espacio, vive los territorios como si ellos no estuvieran allí simbólicamente, como si el enfermo solo estuvieran habitando el espacio físicamente sin una realidad simbólica que dé cuenta de ello o que lo conecte con la circunstancia dada.

La expresión 'de espaldas', en síntesis, representa una pérdida de la autonomía territorial y espacial con la cual se nace y se habita al llegar al mundo. Ya, por ejemplo, el bebé que nace con algún tipo de leucemia (cáncer en la sangre) es restringido de vivir su experiencia de gatear por su casa, de gatear por su habitación y de gatear por el andén para vivir mencionados espacios, desde la inmensidad o estreches de su cama. En este sentido, es claro cómo la autonomía y la libertad espacial son dominadas, controladas y moldeadas por el Cáncer y, en consecuencia, por las prácticas y políticas de medicalización.

En términos generales, se trata de una forma de estar y de habitar el territorio determinada por este actor no humano, además de ser un modo estructurado en que las escalas de representación y construcción de lo territorial se organizan y se le dan al enfermo. Estar de espaldas se refiere a otros sentidos y significados por los que los actores habitan y se apropian de los espacios de la vida cotidiana.

\section{La ventana y la vista al mar: un} intento de estar de frente al mundo real

Anatole Broyard (2013), tras padecer un cáncer de próstata, escribe una serie de ensayos con los cuales publica el libro denominado Ebrio de enfermedad; allí relata su visita al mundo producido por el Cáncer, desde su ingreso a la clínica hasta su egreso. En uno de sus relatos menciona la ventana de una de las habitaciones de la clínica y, a propósito, escribe “desde la ventana de una habitación que no estaba ocupada, contemplé la ciudad, que estaba salpicada de árboles. ¡Qué extraordinario era el mundo real!" (p. 33).

Esta reflexión es clave para entender la objetivación, la significación y la relevancia que en este mundo tienen las ventanas tanto las de la clínica como las de la casa y las del albergue, pero, en especial, las ventanas de la clínica, ya que es allí en donde el enfermo experimenta vehementemente la estructura impuesta por este actor no humano, en tanto, vive bajo normas rígidas que se materializan, por ejemplo, en un aislamiento prolongado del mundo exterior.

En estas condiciones, la ventana no es solo lo que representa en sí; no es solo un inmobiliario más de la clínica, la ventana es, ante todo, un tercer espacio por el cual el enfermo observa y siente 
${ }^{8}$ Es entendido de acuerdo con Deleuze \& Guattari (2012) "como todo el conjunto de materias de expresión que trazan un territorio, desarrollando motivos o paisajes territoriales” (p. 57).

${ }^{9}$ Digo a veces, ya que a raíz de la relación que existe entre el cáncer y la muerte, el futuro que se proyecta no radica sus bases en sueños ni en metas, sino en incertidumbres ambiguas que hacen delirar a los enfermos; por ello, se deja de pensar en esta temporalidad y se prefiere, por ejemplo, pensar en el pasado como un pasado constituido por vivencias y hechos territoriales reales.

\section{tersitarias 42}

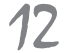

el mundo exterior como si estuviera allí, como si realmente estuviera más afuera que adentro por las sensaciones que le produce y por las imágenes que observa en el transcurso de la hospitalización.

De esta forma, en la clínica no hay nada más preponderante que la ventana, no hay nada más importante que tener el privilegio de que al ingresar a la clínica le asignen una habitación con ventana, que realmente ofrezca una vista al mar, como la llaman los enfermos y el personal asistencial, que le permita al enfermo contemplar el día y la noche, el sol y la lluvia del mundo exterior $y$, así, permanecer, al menos, ubicado temporal y geográficamente en el mundo. Al respecto, los médicos y los demás miembros del equipo asistencial destacan que hay enfermos que no ingresan a la clínica hasta que no les asignen una habitación con ventana.

La ventana, en contraste con la clínica, representa dos asuntos fundamentales para el enfermo; lo primero tiene que ver con la creación de un espacio simbólico que subordina la habitación en sí, y, lo segundo, que es lo más interesante e importante para los enfermos, es la incidencia y dominio que tiene la ventana sobre el tiempo, pues hace que este literalmente vaya más rápido, la ventana descomprime y cataliza el mundo interior de la clínica en la medida en que genera la sensación de ubicación y consciencia del mundo exterior que transcurre; en otros términos, la ventana le permite a quien está internado vivir el día y la noche como si estuviera afuera y no adentro, lo que genera la sensación de rapidez y consciencia del día.

Visto de este modo, las ventanas que tienen vista al mar fungen, de acuerdo con Deleuze \& Guattari (2012), como un ritornelo, ${ }^{8}$ pues quien ingresa por la puerta de la clínica del mundo exterior, al observarlo detenidamente a través de la ventana, se vincula de nuevo con el mundo real, ya que lo visto le despierta recuerdos sobre acontecimientos y hechos significativos que lo transportan metafóricamente a los espacios asociados con estos recuerdos; por lo tanto, el enfermo está físicamente en su habitación recibiendo el tratamiento, pero cognitivamente está jugando fútbol en el polideportivo de su barrio, está en su oficina de trabajo, está en su casa, está con su familia, está en su cama jugando videojuegos o, simplemente, está en cualquier lugar del mundo fuera de la clínica.

En efecto, la ventana, asumida como el ritornelo, recrea estéticamente al interior de la habitación otras continuidades, otros movimientos y otras sensaciones territoriales que van más allá de la experiencia que vive el interno al interior de la clínica, permitiéndole, a través de la cognición, de la imaginación y del lenguaje, situarse en otras realidades, historias y tiempos marcados especialmente por el pasado o por el presente y, a veces, por el futuro. ${ }^{9}$

La ventana permite que, a través de sus cristales, el enfermo experimente la percepción de que el tiempo pasa, transcurre, 
ya que constantemente lo tiene conectado al tiempo "rápido" y "laboral" del mundo exterior que contempla, que observa. Es consciente del cambio del día, cómo este va de la mañana al medio día y de este a la tarde y, luego, a la noche, así como de los cambios de clima. Cosa que no ocurre con aquellos enfermos que están en habitaciones sin ventanas, quienes experimentan con mayor claridad la idea de estar de espaldas al mundo, pues pierden todo tipo de vínculo y conexión con el exterior.

Alberto Pereira es un joven de 18 años que reside en Armenia, pero que por su tipo de cáncer ${ }^{10}$ debe hospitalizarse cada quince días en la clínica de Oncólogos sede Pereira. Él recuerda que la última hospitalización duró treinta y cinco días, pero no fue tan difícil esta vez, al contrario, fue fácil pues durante todo ese tiempo estuvo en una habitación que tenía vista al mar, lo que le permitió dinamizar el tiempo porque estaba conexo con el mundo real.

Cuando estoy en la ventana que da hacia afuera puedo estar un mes o más, el tiempo se me pasa volando, casi ni se siente la hospitalización. En cambio, cuando estoy en las otras ventanas que no tienen vista al mar, el tiempo en la clínica se me hace largo, sufro más y a veces el deseo de regresar a casa me desborda, me deprimo y me canso de todo (Pereira, 2016).

En este marco, es claro que la ventana “introduce el pequeño salón en el vasto mundo" (Bollnow, 1969, p. 148), mete toda la habitación y todo lo que en ella se sitúa en las dinámicas espaciales del vasto mundo. La ventana, en consecuencia, es un espacio a través del cual el enfermo lucha contra el fenómeno de contracción territorial (aislamiento), que significa estar internado por tiempos prolongados en la clínica, ya que esta expande y amplia de nuevo el mundo que ha sido contraído o reducido al interior de la clínica, que ha sido negado por otros actores, lo que les permite, según explican los enfermos, sentirse, aunque sea relativamente, fuera de la clínica.

Además de lo anterior, la ventana que tiene vista al mundo exterior contribuye en términos generales, a mejorar por un lado la calidad de vida de los enfermos al tratamiento, pues disminuye la incidencia de enfermedades mentales como ansiedad, depresión o angustia. Y, por otra parte, favorece a la adherencia de los tratamientos oncológicos, pues los enfermos acceden con mayor facilidad y disposición cuando la habitación que les fue asignada, tiene ventana. Estos dos asuntos, quedan abiertos a ser profundizados en trabajos futuros en los que la ventana, sea la unidad de análisis.

\section{La casa como un ser relativo y la cama como el centro del mundo}

La casa, para quien la habita, es más que la casa, es el hogar que ha sido dibujado, pulido e imaginado a la semejanza de su habitante. De ahí que la casa se establezca,
${ }^{10}$ Se encuentra situado en el mediastino, órgano que está situado cerca al corazón. 
física y simbólicamente hablando, como el rincón del mundo o como el primer universo que nos hacemos al llegar al mundo (Bachelard, 1975); en otras palabras, la casa es un producto de nuestra representación y proyección de intereses. Bajo esta perspectiva intentaré, grosso modo, explicar qué representa y qué significa la casa para el enfermo durante y después de la incidencia en la vida cotidiana de este actor social no humano que, como se ha visto, interfiere en dichas representaciones, proyecciones e interés que sobre la casa se llegan a inscribir para hacerla suya.

Para avanzar en esto, me centraré, particularmente, en tres aspectos reconocidos tanto por los enfermos como por los especialistas participantes de la investigación, que, a mi modo de ver, permiten mostrar e interpretar las singularidades que asume la casa después del hito territorial de este actor no humano en la vida cotidiana de los actores y que, en este caso, tienen que ver con: 1) el Cáncer como un percatarse de ese rincón del mundo, ciertamente, de la existencia física y simbólica de la casa; 2) la casa como extensión tanto del Cáncer como de la continuidad producida por este actor $y$, finalmente, 3 ) la casa como un desprenderse y librarse del mundo concebido y estereotipado del Cáncer.

Estos tres aspectos constituyen de entrada un hallazgo de relevancia, ya que dejan ver cómo la casa, producto de la incidencia prolongada de este actor no humano sobre el enfermo, paulatinamente experimenta una serie de transformaciones estructurales (cambio de lugar de los inmuebles, establecimiento de protocolos de higiene más estrictos) y simbólicos (construcción de nuevos vínculos, por ejemplo, la casa como hogar y como espacio de desahogo), por medio de las cuales ese espacio vivencial, del cual habla Otto Bollnow (1969), asume otras cualidades, otras funciones y otras representaciones; es decir, otras acotaciones y objetivaciones preponderantes en la nueva vida cotidiana de los actores sociales que la habitan. Con esto, no quiero decir que la casa deja de ser el rincón o nuestro primer universo en el mundo; al contrario, lo sigue siendo, pero esta vez bajo otros patrones de gestión, ordenación y manejo del espacio.

La casa, a partir de hito territorial del Cáncer, empieza a ser habitada y acotada de ahora en adelante por el enfermo y también por el actor no humano y por cada una de las prácticas de medicalización establecidas por la clínica como las que tienen que ver, en este caso, con las recomendaciones y restricciones de permanecer en casa aislado del mundo: utilizar diariamente el tapabocas, tener separados los objetos personales del enfermo del resto de la familia, entre otras normas que tienen que ver con la gestión del espacio.

Este tipo de cambios son, quizá, una de las tantas maneras en las que la casa se presenta a raíz del hito territorial del Cáncer y esto que ocurre es fundamental en términos de lo que muestra. Estos ajustes o reconfiguraciones que paulatinamente se van plasmando en la casa develan, 
paradójicamente, que la casa antes del Cáncer no es el espacio preponderante y referente en la vida de quienes la habitan; es, ante todo, un espacio/vivienda contenedora de dichas manifestaciones, representaciones y relaciones que no llegan a dar cuenta de una objetivación de la casa como rincón y eje estructurante del mundo y, en consecuencia, de los demás territorios.

Pero por algo pasan las cosas, porque cuando yo estaba con esa vida de rumbear, de trabajar y de pasear, solo venía a la casa a almorzar, a comer y a dormir. Yo a veces no me daba cuenta de los problemas que estaban pasando en la casa, o de los problemas que tenía mi papá o de los problemas que tenía mi mamá o de los problemas de mi hermano, o lo que estaba pasando en la casa, yo no sabía nada de mi casa. Simplemente no estaba conectada con nada de mi casa, porque todo lo que me importaba y me interesaba está afuera de la casa (Eleonor Ballesteros, 2016).

En otras palabras, la casa antes del Cáncer es confundida con la vivienda física, ya que es asumida por sus huéspedes, como el espacio en el cual vive, duerme, se alimenta, se descansa y se organizan sin llegar esto, a construir una realidad simbólica de ese pequeño mundo o espacio en el que se reflejen los interés, los anhelos, las prácticas $\mathrm{y}$, en última instancia, la personalidad de quien la habita, de quien la vive como suya; ya que el sujeto ha estado o está volcado a otros placeres de la vida externos a la casa, como los amigos, las fiestas y los paseos, en los cuales la casa no tiene mayor relevancia más que la de brindar alimentación y seguridad.

Ahora bien, cuando aparece el Cáncer en lo cotidiano y comienza a incidir en las relaciones de los sujetos, no solo aparece la casa como esa construcción simbólica hecha hogar, sino que, a su vez, aparecen otros territorios de la casa como la ventana, la cama, el cuarto, el baño y la sala, solo por mencionar algunos; y ese aparecer en lo cotidiano radica en que el sujeto se percata de ellos; la enfermedad hace dolorosamente visible a estos espacios, que de ahora en adelante se establecerán como territorios estructurantes para el transcurrir de la vida del enfermo. Es claro entonces, que el Cáncer inspira un relacionamiento distinto de los habitantes con la casa.

La casa representa, además, un librarse del mundo estereotipado de la clínica, ya que, a pesar de tener una serie de recomendaciones, el enfermo, al estar en su mundo, al estar en su rincón en el mundo, al estar en su cuerpo y en su propia alma, territorializa y se apropia de las recomendaciones en función de lo que representa su casa y, de esta manera, disfruta relativamente la estadía, ya que de nuevo experimenta que esta de frente al territorio; por lo tanto, es quien produce y objetiva su casa, su sala, su cuarto y su baño.

Un ejemplo de esto puede ser la hora de despertarse, cuando el enfermo está 
${ }^{11}$ Para un estadio 0, I y II, quizá, la cama no es aún un actor preponderante en la elaboración de las relaciones con los demás espacios o actores; la cama se mantiene en su posición funcional y simbólica que le ha sido designada, la del dormitorio de quienes habitan la casa. Para los estadios III y IV, que son aquellos en los cuales se encuentran la mayoría de los enfermos, la cama no es solo el dormitorio o el lugar de descanso, más que eso, es el espacio sobre el cual viven las demás escalas de representación y manejo del territorio.

\section{territarias 42}

en la clínica debe levantarse antes de las siete de la mañana, pues a esa hora pasan las aseadoras cambiando sabanas y cobijas y, además, las enfermeras realizan el segundo registro de los signos vitales (la primera es a la madrugada), seguidamente de esto, inicia toda una rutina en función del tratamiento en el que se encuentre el enfermo, bien sea, toma de exámenes, toma de imágenes, cirugía, aplicación del medicamento, consulta por psiconcologia o fisioterapia entre otros. En cambio, en casa, puede despertarse a la hora que lo considere necesario, en últimas, es quien gestiona el tiempo, además, no está bajo una rutina médico-administrativa rígida, sin embargo, sí debe cumplir con unos horarios en los que debe tomarse los medicamentos de rehabilitación o de apoyo a su tratamiento base.

En términos generales, la casa constituye la disputa territorial entre el actor no humano y el enfermo, es una disputa por conquistar y dominar los territorios, desde el cuerpo hasta la casa y la ciudad entera; es, en último término, un estar en los territorios como se solía estar. De esta manera, la casa, como materialización de la personalidad de quien la habita, como espejo de las prácticas y discursos de sus huéspedes, experimenta cada una de las sensaciones y emociones que vive, en este caso, el enfermo conquistado por el Cáncer y esto habla, precisamente, de una construcción territorial mediada por los humanos y por los no humanos.

\section{La cama}

De entrada, es necesario advertir que la cama aquí no es pensada, en palabras de Pascal Dibie (1999), como uno de los muebles más importante y comunes de todo el inmobiliario de la casa, sino que es pensada como un actor y como un territorio que, motivado por este actor no humano, asume un papel físico, simbólico y social, tanto en la experiencia misma de vivir con la enfermedad o, incluso, de vivir cualquier otra tipo de perturbación, sino que, a su vez, asume un rol dominante y esencial en la organización, gestión y producción de los demás territorios.

En especial, la cama como actor y como territorio cobra importancia en aquellos casos en los que el enfermo se encuentra en un estadio avanzado (II, III O IV $),{ }^{11}$ ya que pierde, producto de este avance, tanto movilidad física como la libertad y la autonomía territorial de transitar fácilmente por cada uno de los espacios más significativos. Así, la cama asume otra realidad en la medida en que se establece como el territorio eje desde el cual es factible, desde la imaginación y el recuerdo, vivir las demás escalas de representación y organización del mundo. Territorios como la oficina de trabajo, la universidad, el colegio, la escuela, el centro comercial, el parque, las calles, entre otros, son, entonces, objetivados y delimitados desde la inmensidad o estreches de la cama. 
En este sentido, la primera reflexión respecto al dormitorio, a ese espacio en el que se duerme e imagina el vasto mundo, tiene que ver con la forma en que el enfermo se sitúa en él, puesto que pasa física y simbólicamente de estar en una posición vertical, a una posición horizontal; pasa de estar de pie, caminando y recorriendo cada uno de los espacios que estructuran lo cotidiano, a estar acostado, imaginando aquellos territorios que antes eran recorridos autónomamente.

Ahora, acostado en su cama, de acuerdo con Otto Bollnow (1969), el hombre se enfrenta a otro espacio distinto de aquel en el que se mueve de pie (p. 150), metafóricamente hablando, se distancia y cambia de forma o, al menos, experimenta otra curvatura, ya no puede alcanzar los territorios o estar en ellos sin dejar aquella parte anexa a su cuerpo, la cama (Bollnow, 1969).

Sin duda alguna, la cama no es solo el dormitorio, no es solo el lugar de descanso del enfermo o el lugar de aislamiento de la casa y del resto del mundo; la cama, en este caso, representa un potente modo en el que los sujetos o actores humanos o no humanos delimitan, objetivan y producen los territorios, es la forma mediate la cual el enfermo se relaciona física y simbólicamente con el espacio habitado. La cama, en consecuencia, es un mediador entre los actores y el espacio, es una manera en que se significa y se controla una porción del espacio para ser nombrada habitación, sala, baño, casa, clínica, sala de quimioterapia o bunker de radioterapia.

El otro aspecto que se debe destacar se refiere a la cama como el rincón del mundo más íntimo y sublime en el que el enfermo desarrolla toda la vida cotidiana que va desde lo social, lo productivo y lo familiar hasta lo emotivo. Como lo destaca una de las enfermas:

Uno comienza a extrañar su cama, uno siente que las demás camas a pesar de ser una cama, no se siente lo mismo, como uno siente su propia cama. Yo extrañaba mi cama, yo era desesperada por regresar a mi cama, uno ruega para que en la cama de uno le hagan todo, yo extrañe mucho mi camita, uno extraña la cama evidentemente (Eleonor Ballesteros, 2016).

En este marco, es claro que la cama producto de la incidencia de la enfermedad se ordena como un centro de mundo o como un territorio transversal a la experiencia expandida del Cáncer por cada una de las escalas de representación del espacio. De acuerdo con Otto Bollnow (1969), "en la cama es donde comienzan y terminan normalmente los días y la vida entera" (Bollnow, 1969 p. 16) bien sea de un enfermo o de un sano, pero con mayor preponderancia y vehemencia la del enfermo, quien no solo inicia allí los días en función de las prácticas médicas, sino que, también va ajustando su antigua vida alrededor de ella; dicho de otro modo, el 
${ }^{12}$ Caja de Compensación familiar de Caldas.

territarias 42 enfermo comienza a proyectar en la cama diversas actividades de índole social, productivo y simbólico, que antes acostumbraba a hacer fuera de la cama e, incluso, fuera de la casa, ya que eran prácticas que estaban asociadas con territorios externos a la cama y a la casa, pero que ahora por su condición debe traer hasta su cama, representarlos en la inmensidad de esta para actuar sobre ellos, procurando así, alimentar y significar la territorialidad elaborada previamente.

En la cama, el enfermo se alimenta, recibe el tratamiento, lleva a cabo todos sus procesos fisiológicos, recibe la visita de amigos y familiares, trabaja, estudia, duerme, contempla el mundo exterior, espera el paso del día o, simplemente, guarda la esperanza de que regrese todo a la normalidad o, en su defecto, que llegue con apuro la muerte.

En todo sentido, la cama en este caso no representa un encierro o una atadura, al contrario, representa una oportunidad de aprender a estar en los territorios de la vida cotidiana de otro modo no explorado a profundidad por los estudios territoriales. Es, como se ha resaltado, una forma en la que se apropian y se nombran los demás territorios a raíz de la incidencia de este actor no humano. La cama, entonces, por una parte, permite librarse de las dinámicas impuestas por este actor no humano $y$, por otra parte, constituye un aventurarse hacia los placeres de la vida que han sido limitados.

\section{El albergue u hogar de paso. El territorio de la espera y de la esperanza}

\section{Contexto interno y externo del albergue la Misericordia, Manizales}

El albergue Fundación la Misericordia se encuentra en la ciudad de Manizales, está ubicado en medio de las dos avenidas más importantes para la movilidad de la ciudad, la avenida Santander y la avenida Paralela. Se encuentra situado específicamente en la calle $50 \mathrm{~N} .^{\circ} 24-56$, frente a Confa ${ }^{12} \mathrm{de}$ la 50, a una cuadra del Hospital Infantil de Caldas, en el que están los pabellones de hospitalización de Oncólogos de Occidente, tanto de niños como de adultos con cáncer. El recorrido del albergue al hospital infantil lo constituye una zona de funerarias, solo por el recorrido habitual hay dos, desviando a una de las calles se encuentran otras dos funerarias, lo que hace, a mi parecer, complejo y desesperanzador el recorrido bien sea de los enfermos o de los acompañantes (figura 1 ).

El albergue se encuentra divido en tres grandes espacios: ropero (mercado de pulgas), albergue y hogar geriátrico. El ropero es un mercado de pulgas que contribuye al sustento de la fundación, allí reciben donaciones de todo tipo de productos que estén en buen estado, principalmente ropa, muebles y libros, que comercializan para obtener recursos. La parte del albergue se divide en dos plantas: en la primera planta están las oficinas 
Figura 1. Visión panorámica Albergue la Misericordia y

Hospital Infantil de Caldas. Lucía C, 2016

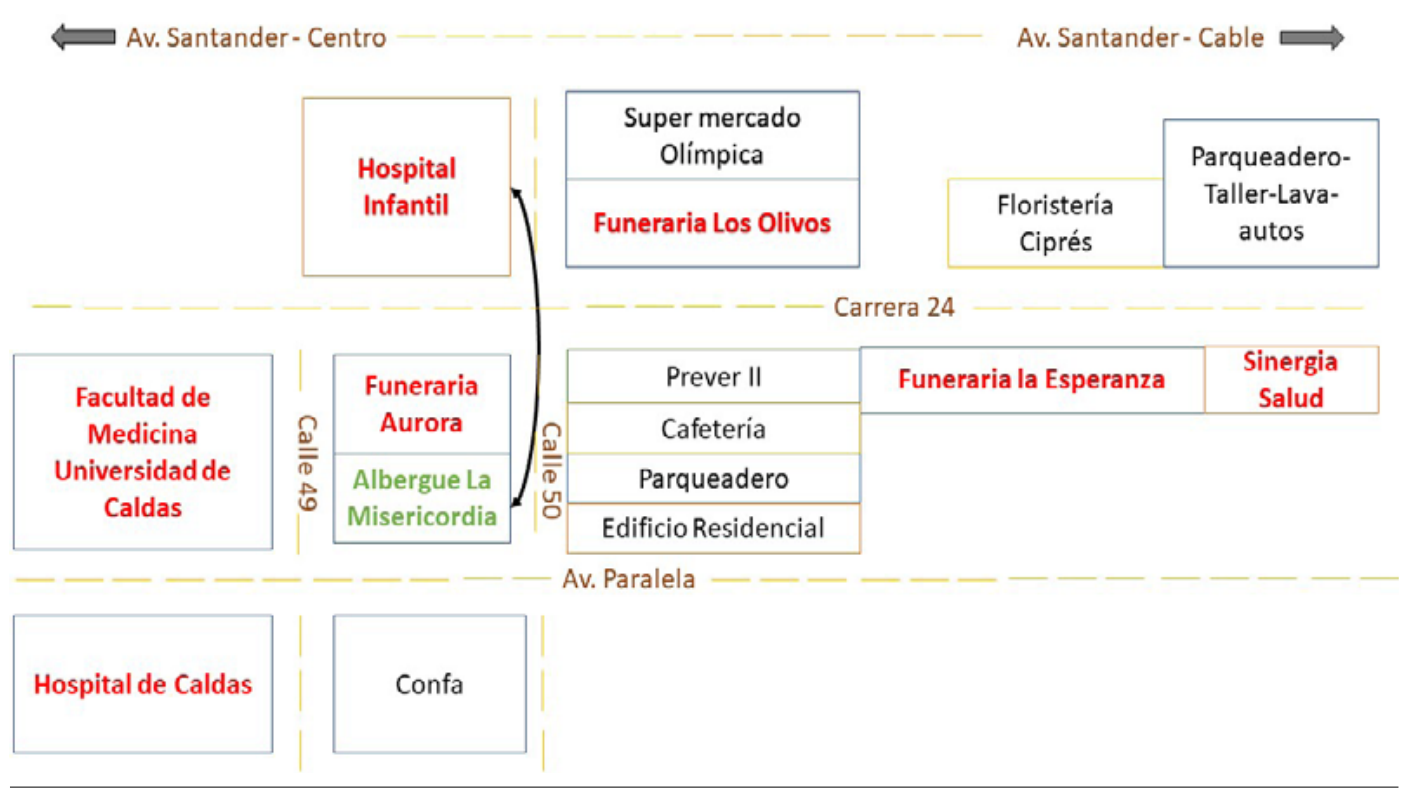

Fuente: Elaboración propia con base en Lucía (2016).

administrativas, el oratorio, las habitaciones del personal, las salas de televisión, las habitaciones 13, 14 y 15, y las zonas de lavandería, cocina y comedor. En la segunda planta se encuentran las habitaciones de la 5 a la 11 , además de las zonas de televisión y las duchas. Las habitaciones 10 y 11 están destinadas para los enfermos de cáncer y sus acompañantes.

El albergue es un servicio gratuito, ${ }^{13}$ el pago se hace por medio de un trueque, quienes ingresan a este lugar deben colaborar con el aseo general de la casa, así como apoyar en lavandería y en la cocina según los turnos asignados por el equipo administrativo, que lo conforman la directora, la coordinadora general del servicio, la jefe de cocina y la jefe de aseo, además de las monjas la Misericordia que prestan su servicio en el albergue. Para acceder al servicio del albergue, los enfermos deben ser remitidos formalmente, bien sea por la Entidad Prestadora de Salud (EPS) o la Institución Prestadora de Salud (IPS), en este caso, por IPS Oncólogos de Occidente. Este servicio se prioriza para aquellos enfermos y acompañantes que vienen de municipios lejanos o de otros departamentos que no tienen familiares en la ciudad de Manizales ni recursos para costearse un hospedaje.
${ }^{13}$ En la actualidad, las discusiones apuntan a que sea la EPS del enfermo la que cubra también los gastos del albergue. territarios 42

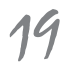




\section{Principales hallazgos}

Sin duda alguna, el albergue, como la clínica es, en este recorrido por la estructura del mundo construido y posibilitado por el Cáncer, un territorio emergente y nuevo que se le presenta tanto al enfermo como a los cuidadores, ya que antes de esta enfermedad no tenían conocimiento o idea alguna de su existencia o de su materialización en el mundo de la vida.

$\mathrm{Al}$ albergue se le asigna, en primera instancia, la noción de territorio emergente, en vista de la novedad simbólica y espacial que representa, ya que, por una parte, su materialización está asociada con las clínicas oncológicas o con aquellas clínicas en las que el común denominador son estancias prolongadas y, por otra parte, porque su estructura interna y externa da cuenta de una producción territorial inusual en la que el principal eje constituyente del habitar y ser en el mundo, es la espera.

Para referirme al primer asunto propuesto en el que planteo que el albergue es una materialización y una extensión de la clínica oncológica, diré que el albergue, de acuerdo con Jorge Sepúlveda (2012), “es una escala más de las múltiples que formarían parte de la génesis o remisión del cáncer" (p. 9). El albergue, como edificio o como casa contigua o no contigua a la clínica oncológica, se presenta como una producción territorial tanto en lo concerniente a lo físico como a lo simbólico de la clínica y del cáncer en sí. Es, en último término, una producción territorial continua de las dinámicas y particularidades de este actor.

El albergue, en este orden de ideas, funge como una de las tantas escalas que constituyen la continuidad territorial que ha sido elaborada y proyectada por este actor no humano en el mundo de la vida de los actores humanos. Es una escala de representación en la que el sujeto enfermo o no enfermo vive una cotidianidad similar a la que se vive en la clínica, puesto que allí no solo experimenta la sensación de estar en espera, sino también, la de estar de espaldas al mundo real, ya que quien habita allí no produce autónomamente la organización del espacio, esto, como en el caso de la clínica, está determinado por las normas del albergue y por las circunstancias de vida tanto del enfermo como de los acompañantes.

Por lo tanto, concebir el albergue como una escala de representación del Cáncer y, en consecuencia, de la clínica oncológica, hace alusión no solo a esa continuidad cerrada que se establece entre lo uno y otro, sino también a la idea de que, en el albergue, se materializa simbólicamente una arquitectura, una organización y una gestión (administración) similar a la de la clínica.

Aunque se presentan variaciones con respecto a la construcción del tiempo y a la forma en que se vive el espacio, en ambas unidades de análisis predominan las camas, las habitaciones, las ventanas, la higiene del espacio y de los objetos, las prácticas de medicalización, el ser relativo 
en el mundo, la presencia de la muerte y la incertidumbre de que se disputa con la vida el dominio del mundo, esto es, el control de la producción y objetivación territorial. Los albergues son territorios multisituados, asociados con el modo en que se produce y se construyen territorios y territorialidades que, en este caso, se encuentran vinculadas a las prácticas, discursos y demarcaciones establecidas e impuestas por el Cáncer.

Este primer andamiaje, referente a la asociación Cáncer-albergue o clínicas oncológicas-albergue, se proyectan como una extensión del Cáncer y, a la vez, se proyecta como la configuración de un espacio inusual, dispuesto y concebido para la espera de quien acompaña al enfermo en este mundo de los enfermos. Dicho en otras palabras, el albergue es, también, "un lugar diseñado de manera institucional para organizar la espera de los grupos que se mueven" (Musset, 2015, p. 306) $y$, en este caso, para los grupos de enfermos de cáncer y acompañantes que viajan y transitan constantemente de un lado a otro en el marco de la estructura continúa definida por este actor no humano.

Allí, en el albergue, los actores, bien sean estos humanos (enfermos, acompañantes y equipo asistencial) o no humanos (Cáncer y medicamentos), habitan en la condición existencial del ser en espera y, fruto de esa condición que se prolonga en el tiempo, se configura un vínculo con el espacio tanto como con los demás actores de este espacio, dicho vínculo permite un trascender de un lugar de espera, como un aeropuerto, a un territorio de la espera como lo es, en este caso, el albergue u hogar de paso.

Cuando el acompañante o el enfermo ingresan al albergue, se encuentran con un mundo estereotipado en función de la espera. Quienes administran el espacio lo hacen sabedores de cada una de las reglas y normas que constituyen el albergue, desde los horarios en los cuales se sirve el desayuno, el almuerzo y la comida, hasta las maneras en que están distribuidas las habitaciones que, en el caso del albergue La Misericordia, están separadas por tipos de enfermedad. Esta "segregación" interna en el uso y manejo del espacio se realiza, precisamente, pensando en el tiempo de espera que comparten los enfermos o familiares de los cancerosos para que así, durante el transcurrir de ese largo y denso periodo, construyan un vínculo compartido en relación con el hecho social y territorial que hoy los une y los mantendrá unidos por un tiempo en el albergue.

Esta unión entre personas sin ningún parentesco físico, más que el social y el simbólico establecido por el actor no humano que los territorializa, facilita la apropiación individual y colectiva de ese espacio o escala de representación del Cáncer como un territorio de la espera y de la esperanza en el que los acompañantes "esperan con paciencia y con esperanza" el transcurrir del tratamiento y la pronta recuperación de su hijo, de su sobrino o territarias 42 
${ }^{14}$ No queremos decir que la movilidad de los actores desaparezca, sino que aún se mantiene, pero no como un deseo del enfermo o del acompañante, sino como una imposición del cáncer.

\section{territarias 42}

de su nieto. Esta relación espera-esperanza viene muy ligada a la idea de la vida en el tuberculario de Thomas Mann (2014), ya que, en el caso del enfermo de tuberculosis, este deposita su esperanza de recuperación en estas instituciones y, en especial, en las tardes de tumbona en la terraza.

En el caso del Cáncer, la espera-esperanza se encuentra soportada y dinamizada en parte, en el oratorio que está situado en el centro de la casa; por lo tanto, la esperanza, como una estrategia de apropiación adicional que constituye la dimensión existencial de la espera, se objetiva y discurre motivando la producción territorial de los acompañantes; esto quiere decir que delimita y constituye, al mismo tiempo, la territorialidad del espacio.

Dicho de otra forma, la relación ontológica entre la espera y la esperanza, que en último término produce la territorialidad del albergue como territorio de la espera, está situada y marcada por una temporalidad en la que el estar y el habitar en la espera se caracteriza por el discurrir de una estructura pasada (recuerdos) a una estructura presente (espera) y a una estructura futura (esperanza) (González, 2016) que recrean y mantienen la esperanza de quienes esperan. Sin embargo, estas estructuras paralelamente, de acuerdo con la particularidad de la enfermedad y al nivel de aflicción del enfermo y de los acompañantes, también pueden recrear y proyectar un futuro incierto y desesperanzador, generando así otras disposiciones y significados que mediarán los procesos de territorialización.

Un futuro desesperanzador ocurre, por ejemplo, cuando al enfermo en su primera fase de tratamiento le controlan su enfermedad, pasa a una segunda fase denominada remisión que corresponde a un seguimiento constante de la evolución del tratamiento. Pasados unos meses o años de control, de nuevo, digámoslo de alguna manera, aparece la enfermedad y esta vez, con mayor ímpetu. Este hallazgo es conocido en el mundo oncológico como recaída, que implica iniciar de nuevo un tratamiento, pero esta vez más agresivo, lo que alimenta la desesperanza tanto del enfermo, como de sus cuidadores o acompañantes. Así, el albergue puede estar mediado, de acuerdo con la experiencia y aflicción de los actores, por la esperanza o por la desesperanza.

Así las cosas, la dimensión existencial del ser y del estar en los territorios es una espera constante. Esta dimensión se establece como el eje catalizador y estructurante de las prácticas y discursos de quienes ingresan a este "nuevo" e inusual espacio posibilitado por el Cáncer. En consecuencia, quien arriba al albergue, lo hace consciente de su nueva condición de ser y de estar en el mundo, pero es, precisamente, en el albergue en el que, producto de sus prácticas y discursos que lo constituyen, que se hace aún más tangible esa dimensión existencial de la espera, en tanto este está diseñado, como lo hemos dicho, para administrar la espera de los 
viajeros, como ocurre con el albergue La Misericordia de Manizales.

La espera como condición del habitar representa la manera en la que el espacio se nos da como un territorio de la espera $y$, también, como un modo en el que el tiempo discurre, ya que el actor, producto de la enfermedad, no se encuentra terciado por el deseo autónomo de la movilidad, ${ }^{14}$ sino por la imposición o establecimiento de la espera temporal, momentánea o fugaz en el mundo (Hiernaux, 2006). El tiempo, en este caso, se caracteriza por ser alargado, denso, difuso y extraño producto tanto de las disposiciones normativas (restricciones de uso o visita de ciertos espacios, reposo y cotidianidad administrada solo por mencionar algunos), como de las prácticas de medicalización que constituye la continuidad territorial estereotipada y normada por este actor no humano.

En este orden de ideas, el territorio de la espera es, ontológicamente, una cuestión del ser en el mundo en el que lo fundamental es la dimensión existencial de la espera (Musset, 2015, p. 306). En el albergue hay un despliegue de una serie de dimensiones o formas de ser y de estar en función de las emociones físicas y corporales. Sea alegre, aliviado, triste o embargado por una incertidumbre inusual, siempre se está y se estará a la espera como en un gran viaje en transatlántico, no se deja de estar a la espera ni en lo uno ni en lo otro. Por lo tanto, el albergue, en último término, no es más que la extensión de un mundo y la representación de una condición existencial en el mundo que objetiva las formas del habitar y la manera en que se nos dan y se nos proyectan los territorios.

\section{Conclusiones}

Hablar de Cáncer es referirse a un actor social no humano, geohistórico que da cuenta de otra imagen y de otra manera en las que el mundo, la vida cotidiana y los espacios habitados por los demás sujetos sean humanos o no humanos (como la cama, el televisor, la puerta y la ventana) se nos presentan y se nos proyectan en lo cotidiano. La representación del Cáncer sea por medio de las metáforas, de las políticas y de los grandes espacios arquitectónicos que se establecen en la ciudad, no solo da cuenta de otras dinámicas que se inscriben en el territorio, sino también, de otras maneras singulares de habitar los espacios y de producirlos. Visto de esta manera, la vivencia del Cáncer implica enfrentarse a un nuevo espacio, pero, en este caso, mediado tanto por actores humanos como por actores no humanos que, a pesar de ser el mismo espacio físico, las prácticas y los discursos, así como las estrategias de ordenación y asentamiento proyectados por ambos actores evidencian la configuración de otras territorialidades y continuidades antes no vistas, ni imaginadas por los enfermos.

Lo que me interesa destacar primordialmente es la "renovación" simbólica, principalmente, $\mathrm{y}$ física que en ocasiones territarias 42

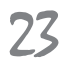


experimenta cada uno de los espacios significativos de los actores humanos que se ven afectados por el Cáncer; entre tanto, estos son objetivados a partir de un cimiento arquitectónico representado en las prácticas y discursos de medicalización.

De esta manera, es otra territorialidad la que se configura, una territorialidad distinta a la que se habitaba y vivía antes del Cáncer y en la cual las trayectorias de un lugar a otro se caracterizan esencialmente por ser una clase de circuito cerrado y aislado, en el que los sujetos van de un punto a otro sin "salirse del camino"; van de la casa a la clínica y de la clínica a la casa, sometidos a una serie de restricciones y recomendaciones que no les permiten ir más allá de los bordes o fronteras sugeridas para el desplazamiento. Son, en este caso, trayectorias administradas fielmente acorde a modelos de atención o a modelos de tratamiento que no dan posibilidad al enfermo de vivir autónoma y libremente el vasto espacio que se le muestra a partir del momento en el que abandona su cama y se inserta en el mundo externo que está fuera de la casa.

La estructura en la que se encuentran los territorios determinados por el Cáncer se caracteriza, valga la redundancia, por las propiedades estructurantes que la constituyen y la objetivan. Propiedades que, como se logró evidenciar en el ejercicio de investigación, se materializan en una serie de huellas mnémicas que marcan y delimitan en tiempo y espacio el territorio. Estas huellas pueden ser físicas, como los efectos secundarios de los tratamientos, o simbólicas, como la transformación del sentido de la vida y, por ende, de los trayectos del enfermo sobre el espacio.

\section{Referencias}

Bachelard, B. (1975). La poética del espacio. México: Fondo de Cultura Económica. Bollnow, F. (1969). Hombre y espacio. Barcelona: Editorial Labor S. A.

Bozzano. H. (2000). Territorios reales, territorios pensados, territorios posibles: Aportes para una teoría territorial del ambiente. Buenos Aires: Editorial Espacio.

Broyard, A. (2013). Ebrio de enfermedad. Segovia: Editorial La uña rota.

Deleuze, G. \& Guattari, F. (2012). Mil mesetas. Capitalismo y esquizofrenia. Barcelona: Pretextos.

Dibie, P. (1999). Etnología de la alcoba. El dormitorio y la gran aventura del reposo de los hombres. Barcelona: Editorial Gedisa.

Foucault, M. (2012). El nacimiento de la clínica: Una arqueología de la mirada médica. Madrid: Siglo XXI Editores.

Giddens, A. (1995). La constitución de la sociedad: bases para la teoría de la estructuración. Buenos Aires: Editorial Amorrortu.

Giraut, F. (2013). Territorio multisituado, complejidad territorial y posmodernidad territorial: herramientas conceptuales relevantes para abordar las

Milton VelásQuez Arias 
territorialidades contemporáneas. L'Espace Géographique, (42), 293-305.

Goffman, E. (2001). Internados. Ensayos sobre la situación social de los enfermos mentales. Buenos Aires: Editorial Amorrortu.

González, A. (2016). Territorio y espera. Hacia un análisis del habitar los territorios de la espera. Aportes epistemológicos desde la geografía para entender la territorialidad. Departamento de Geografia, (4), 45-62.

Garzón, J. (2002). Tras el poder de las péndolas. Plumaditas periodísticas de Agua de Dios. Apuntes para la historia de Agua de Dios.

Haesbaert, R. (2004). El mito de la desterritorialización. Del fin de los territorios a la multiterritorialidad. México: Editorial Siglo XXI.

Hiernaux, D. (2006). Geografía de los tiempos y los espacios efímeros y fugaces. En J. Nogué \& J. Romero (Eds.), Las nuevas geografias (pp. 75-92). Valencia: Ed. Tirant lo Blanch (Colección Crónica).

Latour, B. (2008). Reensamblar lo social. Una introducción a la teoría actor/ red. Buenos Aires: Editorial manantial.

Nancy, J. L. (2007). El intruso. Madrid: Editorial Amorrortu.

Mann, T. (2014). La montaña Mágica. Novena reimpresión. Buenos Aires: Editorial Edhasa.

Musset, A. (2015). Habitar los territorios de la espera. Una nueva dimensión de la geografía social. De los lugares de la espera a los territorios de la espera. Una nueva dimensión de la geografía social. Documentos de análisis Geografía, 61(2), 305-324.

Nates, B. (2010). Soportes teóricos y etnográficos sobre concepto de territorio. Revista Co/herencia, 8 (14), 209-229. Raffestin, C. (2011). Por una geografía del poder. México: Colegio de Michoacán. Sacks, O. (2002). El hombre que confundió a su mujer con un sombrero. Barcelona: Editorial Anagrama.

Sepúlveda, J. (2012). Oncología y ontologia: Un análisis semiótico-material del cáncer. (Tesis de doctorado, Universidad Autónoma de Barcelona, Barcelona, España).

Tuan, Y. F. (2007). Topofilia. El estado de las percepciones, actitudes y valores sobre el entorno. Santa Cruz de Tenerife: Editorial Melusina.

Turner, V. (1980). La selva de los símbolos. Aportes del ritual Ndembu. Ciudad de México: Siglo XXI Editores.

Velázquez, A. M. (2018). Cáncer y territorios. (Tesis de Maestría, Universidad de Caldas, Manizales, Colombia). Recuperado de https://10a5b5406d01-4cd6-95al-e24047cl5abc. filesusr.com/ugd/e52256_dc04b382f2b44ae0b930e8b72947380d.pdf Vergara, A. (2017). Estudios sobre el territorio: métodos y teorías. Conflicto, actores, emosignificaciones, estéticas y simbolismos. Lima: Editorial Pres Producciones estratégicas. 